\title{
The influence of islamic culture on information privacy: Case of malaysia's computer professionals
}

\author{
Wan Abdul Rahim Wan Mohd Isa, Ahmad Iqbal Hakim Suhaimi, Nurulhuda Noordin, \\ Mohd Sabry Mohd Safiq \\ Faculty of Computer and Mathematical Sciences, Universiti Teknologi MARA, Malaysia.
}

\begin{tabular}{|c|c|}
\hline Article Info & ABSTRACT \\
\hline Article history: & \multirow{8}{*}{$\begin{array}{l}\text { In today's era of vulnerability and volatility, technologies in an organization } \\
\text { evolving faster than the traditional landscape. Thus, sets the stage for trust and } \\
\text { privacy concern for all the data that flying around in the database. Research on } \\
\text { cultural aspects toward privacy starting to attract more ongoing research effort } \\
\text { especially in Islamic religious culture. Islam gives great importance to the } \\
\text { fundamental human right to privacy. This study aims to investigate Islamic cultural } \\
\text { influences on Malaysia's computer professionals' self-regulatory efficacy towards } \\
\text { the protection of personal information privacy by adapting the research frameworks } \\
\text { of previous works. Further, data for this research obtained through the survey with } \\
\text { computer professionals. Out of } 226 \text { respondents, } 208 \text { data are valid and usable for } \\
\text { this study. Spearman's Rank Order Correlation was used to determine the } \\
\text { relationship between culture and Information privacy self-regulatory efficacy } \\
\text { dimensions. The findings from this research could provide a better understanding of } \\
\text { the subject matter and be used as the basis for future studies. }\end{array}$} \\
\hline Received Feb 10, 2020 & \\
\hline Revised Apr 6, 2020 & \\
\hline Accepted Apr 20, 2020 & \\
\hline Keywords: & \\
\hline Computer professional & \\
\hline Information privacy & \\
\hline Islamic culture & \\
\hline
\end{tabular}

Copyright $@ 2020$ Institute of Advanced Engineering and Science. All rights reserved.

\section{Corresponding Author:}

Wan Abdul Rahim Wan Mohd Isa,

Faculty of Computer and Mathematical Sciences,

Universiti Teknologi MARA,

40450 Shah Alam, Selangor, Malaysia.

Email:wrahim2@uitm.edu.my

\section{INTRODUCTION}

The present digital age where most data are managed and stored by computers has resulted in the inevitable discussion concerning information privacy. This subject has become a popular topic and is widely debated in recent years. Triggered by the rapid technological advancement, the government and private sector actively gathered the public's information and this rising concern on the safety of their data [1].

Another factor that may influence the insider's actions towards the protection of information privacy is cultural influence. Although societies value some form of privacy, there are significant differences in the concept of confidentiality across cultures. Culture could influence the concept of privacy as to when protection is needed and the level of its importance [1].

In order to investigate the influence of Islamic cultural values against information privacy, it is critical first to determine the cultural dimensions of Islam. Islamic cultural values derived from Hofstede's Cultural Dimensions Theory. Five cultural aspects are (1) Power Distance, (2) Long-term/Short-term Orientation, (3) Uncertainty Avoidance, (4) Masculinity/ Femininity and finally is (5) Individualism/ Collectivism [2]. Hofstede's cultural dimensions on Malaysia showed that the country scored high in Power Distance, low in Individualism, medium in Masculinity, low in Uncertainty Avoidance, and small in Long Term Orientation [3]. The lack of empirical study on the Islamic cultural values has prompted for empirical research on this subject matter, before investigating the relationships of these values with Information Privacy dimensions. This study aims to investigate Islamic cultural influences on Malaysia's computer professionals' self-regulatory efficacy towards the protection of personal information privacy by adapting the research frameworks of previous works. 


\section{LITERATURE REVIEW}

This section can be divided into four main topics, which are information privacy, Hofstede's cultural theory, Islamic cultural values based on Hofstede's cultural theory and framework based on self-regulatory efficacy dimensions. Islamic cultural values from this research derived from Hofstede's cultural theory which then become an input to generate hypothesis against self-regulatory efficacy dimensions in the attempt to investigate their correlations.

\subsection{Information privacy}

The evolution of technology further worsens the threat to information privacy. The Internet does not only enable unlimited communication, but it also disseminates users' personal information on the internet, whether intended or not. Personal details that used to be on paper are now preserved indefinitely in digital form in vast databases, making it very hard to control the privacy of one's personal information.

\subsection{Hofstede's cultural dimensions theory}

There are five cultural dimensions which are (1) Power Distance, (2) Long-term/Short-term Orientation, (3) Uncertainty Avoidance, (4) Masculinity/ Femininity and finally is (5) Individualism/ Collectivism [2].

a) Power Distance: Power Distance refers to how unequal distribution of power in society impact the less powerful members [2]. In other words, how less powerful the community able to accept unequal power distribution from a robust community.

b) Individualism/Collectivism: Individualism refers to how people take charge of their one's self and their won relatives or families. On the contrary, collectivism refers to a collective of people who formed a cohesive and robust bond between them, which created undeniable and unbreakable loyalty [2].

c) Masculinity/Femininity: Modesty and caring values for both men and women in femininity society are higher as compared to Masculine culture [2]. On the other hand, men and women are competitive and assertive in Masculinity society, but the level of competitiveness for women is not the same as men.

d) Long-term/Short-term Orientation: Long Term Orientation (LTO) prepares themselves for the future by sacrificing or delaying their short-term material and emotional satisfaction [2]. In other words, the member of this society focused on future events. A community with LTO tend to value perseverance and being able to adapt quickly. Contrarily, STO refers to a culture that put the present and past event as their high priority as compared to the future. A society with Short-term orientation tends to value their heritage, appreciate their current social order, and to fulfill their social duty.

e) Uncertainty Avoidance: Uncertainty Avoidance, on the other hand, refers to how unstructured or unknow situation threatens the society within members of organizations and institutions. The community in an organization or institutions with High Uncertainty Avoidance (HUA) implement rules, laws, beliefs in absolute truth, and more to reduce the probability of ambiguous situations [2].

\subsection{Islamic cultural dimensions}

This section discusses the relationship of Hofstede's cultural dimensions against Islamic cultural values. The objective is to identify whether Islamic culture values nurture some of the cultural aspects stated by Hofstede [3].

a) Power Distance: Islam is High Power Distance because Muslims behave according to Al-Quran, Hadith \& Sunnah [4]. Muslims rely on the holy book of Al-Quran, prophet, and authoritative sources as their primary source of guidance.

b) Individualism/Collectivism: Islam emphasizes both Individualism (IDL) and Collectivism (COL) group members [4].

c) Masculinity/Femininity [4]: Islam shows strict behaviour toward humankind and demand caring behaviour toward humanity at the same time. This is supported by the holy book of Al- Quran, where a similar reward for ethical behaviour and the same punishment for unethical behaviour will be given all humans regardless of their sexes to Allah.

d) Long-term/Short-term Orientation: Islam is STO because good and evil deeds came from universal guidelines set based on prior knowledge and possessing virtues [4]. Virtues had been determined in the Hadith and Quran [5, 6].

e) Uncertainty Avoidance: Islam is High Uncertain Avoidance (HUA), namely due to the nature of Muslims that concern about truth [4]. The absolute truth had been determined in the Quran [6]. Islam is High Uncertain Avoidance (HUA) because Islam reduces the amount of uncertainty by endorsed culture with high rule-oriented such as laws, rules, and regulations [4]. 


\subsection{Information privacy self-regulatory efficacy dimensions}

There are three different dimensions in information privacy self-regulatory efficacy, which are Protection, Non-distribution, and Non-acquisition [7].

a) Protection: Protection dimension refers to the ability of the person to protect the information privacy of others by overcoming the challenge levels of improper monitoring, privacy invasion, and improper storage [7].

b) Non-distribution: Non-distribution dimension describes how a person able to avoid him or herself from distributing information of others to safeguard the privacy of this information. The challenge levels of this dimension are improper transfer and internal/external unauthorized secondary use [7].

c) Non-acquisition: Non-acquisition dimension describes the person's self-confidence to refuse to acquire and unauthorized manipulation of customer's data to ensure information privacy [7].

\section{METHOD}

\subsection{Sample}

Data for this research obtained through the survey with computer professionals (Muslims). Data collection were carried for one and a half month, where a total of 226 respondents participated. Out of 226 respondents, 208 data are valid and usable for this study.

\subsection{Research model}

The following Figure 1 provides adapted research model of Islamic cultural influences on information privacy self-regulatory efficacy [8] used in this research.

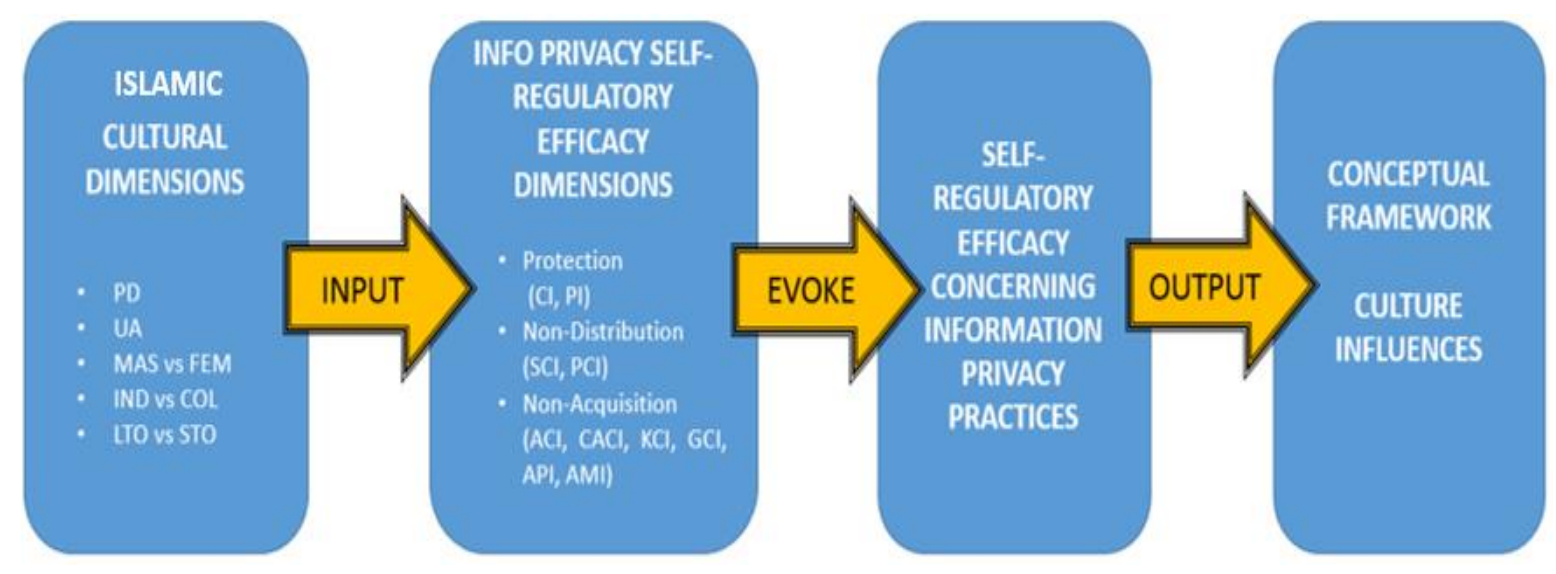

Figure 1. Adapted research model of cultural influences on information privacy self-regulatory efficacy [8].

\subsection{Research hypotheses}

The following set of hypotheses are formulated in the attempt to learn about the relationships between Islamic cultural values (independent variables) and Information Privacy Self-Regulatory Efficacy dimensions (dependent variables). Below shows the list of hypotheses for this research:

a) 'Protection' and 'Power Distance'

$\mathrm{H}_{0}$ : There is no relationship between 'Protection' and 'Power Distance.'

$\mathrm{H}_{1}$ : There is a relationship between 'Protection' and 'Power Distance.'

b) 'Protection' and 'Individualism versus Collectivism'

H20: There is no relationship between 'Protection' and 'Individualism versus Collectivism.'

H21: There is a relationship between 'Protection' and 'Individualism versus Collectivism.'

\section{c) 'Protection' and 'Masculinity versus Femininity'}

H30: There is no relationship between 'Protection' and 'Masculinity versus Femininity.'

H31: There is a relationship between 'Protection' and 'Masculinity versus Femininity.' 
d) 'Protection' and 'Uncertainty Avoidance'

H40: There is no relationship between 'Protection' and 'Uncertainty Avoidance.'

H41: There is a relationship between 'Protection' and 'Uncertainty Avoidance.'

e) 'Protection' and 'Long Term Orientation versus Short Term Orientation'

$\mathrm{H} 5_{0}$ : There is no relationship between 'Protection' and 'Long Term Orientation versus Short Term Orientation.'

H51: There is a relationship between 'Protection' and 'Long Term Orientation versus Short Term Orientation.'

f) 'Non Distribution' and 'Power Distance'

H60: There is no relationship between 'Non-Distribution' and 'Power Distance.'

H61: There is a relationship between 'Non-Distribution' and 'Power Distance.'

g) 'Non Distribution' and 'Individualism versus Collectivism'

H70: There is no relationship between 'Non-Distribution' and 'Individualism versus Collectivism.'

H71: There is a relationship between 'Non-Distribution' and 'Individualism versus Collectivism.'

h) 'Non Distribution' and 'Masculinity versus Femininity'

H80: There is no relationship between 'Non-Distribution' and 'Masculinity versus Femininity.'

H81: There is a relationship between 'Non-Distribution' and 'Masculinity versus Femininity.'

i) 'Non Distribution' and 'Uncertainty Avoidance'

H90: There is no relationship between 'Non-Distribution' and 'Uncertainty Avoidance.'

H91: There is a relationship between 'Non-Distribution' and 'Uncertainty Avoidance.'

j) 'Non Distribution' and 'Long Term Orientation versus Short Term Orientation'

H100: There is no relationship between 'Non-Distribution' and 'Long Term Orientation versus Short Term Orientation.'

H101: There is a relationship between 'Non-Distribution' and 'Long Term Orientation versus Short Term Orientation.'

k) 'Non Acquisition' and 'Power Distance'

H110: There is no relationship between 'Non-Acquisition' and 'Power Distance.'

H111: There is a relationship between 'Non-Acquisition' and 'Power Distance.'

l) 'Non Acquisition' and 'Individualism versus Collectivism'

H120: There is no relationship between 'Non-Acquisition' and 'Individualism versus Collectivism.'

H121: There is a relationship between 'Non-Acquisition' and 'Individualism versus Collectivism.'

m) 'Non Acquisition' and 'Masculinity versus Femininity'

H130: There is no relationship between 'Non-Acquisition' and 'Masculinity versus Femininity.'

H131: There is a relationship between 'Non-Acquisition' and 'Masculinity versus Femininity.'

n) 'Non Acquisition' and 'Uncertainty Avoidance'

H140: There is no relationship between 'Non-Acquisition' and 'Uncertainty Avoidance.'

H141: There is a relationship between 'Non-Acquisition' and 'Uncertainty Avoidance.'

o) 'Non Acquisition' and 'Long Term Orientation versus Short Term Orientation'

H150: There is no relationship between 'Non-Acquisition' and 'Long Term Orientation versus Short Term Orientation.'

H151: There is a relationship between 'Non-Acquisition' and 'Long Term Orientation versus Short Term Orientation.'

\section{ANALYSIS AND FINDINGS}

\subsection{Islamic cultural dimensions}

The survey questionnaire also includes the Islamic cultural values calculated based on VSM 2008 to determine the Hosftede cultural dimensions based from the respondents. Islamic cultural values based on the Values Survey Module (VSM) calculated in the Table 1. This concluded that the Islamic cultural value dimensions of the respondents involved in this research are: 
1) Low Power Distance (LPD),

2) Collectivism (COL),

3) Femininity (FEM),

4) Low Uncertainty Avoidance (LUA) and

5) Short Term Orientation (STO).

Table 1. Index for Islamic cultural values

\begin{tabular}{ccc}
\hline \multirow{2}{*}{ Dimension } & \multicolumn{2}{c}{ VSM 2008 Outcome } \\
& Index value & Result \\
\hline LPD vs SPD & -5.52 & LPD \\
IDV vs COL & 18.34 & COL \\
MAS vs FEM & -3.86 & FEM \\
LUA vs HUA & -10.14 & LUA \\
LTO vs STO & 9.39 & STO \\
\hline
\end{tabular}

\subsection{Spearman's rank order analysis}

The Spearman's Rank Order Correlation method was used to (1) identify significant cultural dimensions (independent variables) that influence the information privacy self-regulatory efficacy dimensions (dependent variables), and (2) to determine the direction of each relationship. The statistical analysis result showed that only two hypotheses were supported, while the remaining 13 were rejected due to the insignificant correlation level of each hypothesis. Result of Spearman's Rank Order Correlation between Cultural Dimensions and Information Privacy Self-Regulatory Efficacy in Table 2.

Table 2. Results of spearman's rank-order correlation between cultural dimensions and information privacy self-regulatory efficacy

\begin{tabular}{ccccc}
\hline $\begin{array}{c}\text { Information Privacy Self- } \\
\text { Regulatory Efficacy Dimensions }\end{array}$ & Islamic Cultural Dimensions & Correlation Coefficient & Sig & Hypothesis Test \\
\hline Protection & LPD & 0.263 & 0.000 & H1 Supported \\
& COL & -0.080 & 0.249 & H2 Rejected \\
& FEM & -0.084 & 0.230 & H3 Rejected \\
& LUA & -0.104 & 0.134 & H4 Rejected \\
& STO & 0.034 & 0.623 & H5 Rejected \\
Non Distribution & LPD & 0.148 & 0.033 & H6 Supported \\
& COL & -0.032 & 0.644 & H7 Rejected \\
& FEM & -0.035 & 0.617 & H8 Rejected \\
& WUA & -0.064 & 0.358 & H9 Rejected \\
& STO & 0.104 & 0.135 & H10 Rejected \\
Non-Acquisition & LPD & 0.069 & 0.323 & H11 Rejected \\
& COL & -0.014 & 0.836 & H12 Rejected \\
& FEM & -0.072 & 0.301 & H13 Rejected \\
& LUA & -0.042 & 0.548 & H14 Rejected \\
& STO & 0.161 & 0.020 & H15 Supported \\
\hline * Statistically significant relationship $(p<0.05)$ & & & &
\end{tabular}

Table 2 shows the result of the Spearman's Rank Order Correlation indicated that Hypothesis H1 had shown a significant, positive, and weak relationship between 'Low Power Distance' (LPD) and 'Protection' (rho= .263, p<0.05). Hypothesis H6 also showed a positive and very weak relationship between Low Power Distance' (LPD) and 'Non-Distribution' (rho $=.148, \mathrm{p}<0.05$ ). Finally, hypothesis H15 showed a positive and very weak relationship between 'Short Term Orientation' and 'Non-Acquisition' (rho = .161, p<0.05).

Society in 'Low Power Distance' is less likely to corrupt. This is because they tend to more openly express themselves, having a disagreement with a leader's actions, and expect to be more involved and prefer to be consulted rather than to be told what to do on their work [2]. These values reduce corruption due to their transparency [9]. Based on the positive relationship between 'Weak Power Distance' (LPD) and 'Protection' dimensions, we can conclude that information privacy in Low Power Distance society is more likely to be protected. Hence, supported hypothesis H1.

Similarly, based on the positive relationship between 'Low Power Distance' (LPD) and 'NonDistribution' dimensions, we can conclude that information privacy in Low Power Distance society is not like to distribute information without consent. Hence, supported hypothesis H6. On the other hand, a society with 'Short Term Orientation' can foster virtues based on present and past and high respect on tradition. Thus, this will prevent them from taking any advantages in the situation to jeopardize or illegally access the data 
which support hypothesis H15. The summary of findings as shown in Table 3. The summary of findings may be used as reference to various domains such as for cloud computing [10-22] and IoT [23 - 25].

Table 3. Summary of findings

\begin{tabular}{cccc}
\hline Self-Regulatory Efficacy Dimensions & Culture Dimensions & Relationship Direction & Relationship Strength \\
\hline Protection & LPD & Positive relationship & Weak \\
Non-Distribution & LPD & Positive relationship & Very Weak \\
Non-Acquisition & STO & Positive relationship & Very Weak \\
\hline
\end{tabular}

\section{CONCLUSION}

With the support of empirical evidence, it is clear that this research has achieved its aim of investigating the Islamic culture influences on Malaysia's computer professionals' self-regulatory efficacy towards the protection of personal information privacy. Based on the empirical findings, it is proven that one's self-regulatory efficacy towards information privacy is partly influenced by culture. The result of the empirical analysis shows that there are three valid relationships that exist in cultural and information privacy. In conclusion, this research, through its literature review and empirical findings, shall provide a better understanding and direction for future research on the subject of cultural influence towards one's information privacy self-regulatory efficacy.

\section{ACKNOWLEDGEMENTS}

This research is funded by the Research Entity Initiative (REI), Universiti Teknologi MARA, Malaysia. (Project Code: 600-IRMI/REI 5/3 (013/2018)).

\section{REFERENCES}

[1] S. Samsuri and Z. Ismail, Z, "Personal medical information management: The information privacy culture of asian countries," Journal of Economics, Business and Management, vol. 1, no. 4, pp. 329-333, 2013.

[2] G. Hofstede, "Dimensionalizing cultures: The hofstede model in context. online readings in psychology and culture," International Association for Cross-cultural Psychology, vol. 2, no. 1, pp. 1-26, 2011.

[3] L. Lim, "Work related values of Malays and chinese Malaysians," International Journal of Cross-Cultural Management, vol. 1, no. 2, pp. 209-226, 2001.

[4] W. A. R. Wan Mohd Isa, N. L. Md Noor, N. L. and S. Mehad, "Inducting the dimensions of islamic culture: A theoretical building approach and website information architecture design application," 21st International Symposium Human Factors in Telecommunication: User Experience of ICTs, 2008, pp. 89-96, 2008.

[5] Sahih Muslim, vol. 1, Book of Prayers, Hadith 805.

[6] T. Itani, Quran in English: Modern English Translation. Clear and Easy to Understand, ClearQuran.com, 2014.

[7] F. Y. Kuo, C. S. Lin and M. H. Hsu, "Assessing gender differences in computer professionals' self-regulatory efficacy concerning information privacy practices," Journal of Business Ethics, vol.73, pp. 145-160, 2007.

[8] W. A. R. Wan Mohd Isa, A. Mohd Lokman and N. L. Md Noor, "Investigating culture influences to information privacy," knowledge management international conference (KMICe) 2014, pp. 332-337, 2014.

[9] E. McLaughlin, "Culture and corruption, an explanation of the differences between scandinavia and Africa," American International Journal of Research in Humanities, Arts and Social Sciences, vol. 2, no. 2, pp. 85-91, 2013.

[10] R. F. Olanrewaju, T. Islam, O. O. Khalifa and F. E. Fajingbesi, "Data in transit validation for cloud computing using cloud-based algorithm detection of injected objects," Indonesian Journal of Electrical Engineering and Computer Science (IJEECS), vol. 10, no. 1, pp. 348-353, 2018.

[11] S. Potluri and K. S. Rao, "Optimization model for QoS based task scheduling in cloud computing environment," Indonesian Journal of Electrical Engineering and Computer Science (IJEECS), vol. 18, no. 2, pp. 1081-1088, 2020.

[12] G. Panatula, K S. Kumar, D. E. Geetha and T. V. S. Kumar, "Performance evaluation of cloud service with hadoop for twitter data," Indonesian Journal of Electrical Engineering and Computer Science (IJEECS), vol. 13, no. 1, pp. 392-404, 2019.

[13] I. O.-Ayo, T.-A. Williams, O. A.-Alli and J. Yahaya, "Systematic mapping study of economic and business models of cloud services," Indonesian Journal of Electrical Engineering and Computer Science (IJEECS), vol. 18, no. 2, pp. 987-994, 2020.

[14] F. S. Ali, H. N. Saad, F. H. Sarhan and B. Naaeem, "Enhance manet usability for encrypted data retrieval from cloud computing, " Indonesian Journal of Electrical Engineering and Computer Science (IJEECS), vol. 18, no. 1, pp. 64-74, 2020.

[15] C. Jittawiriyanukoon, "Cloud computing based load balancing algorithm for erlang concurrent traffic, ” Indonesian Journal of Electrical Engineering and Computer Science (IJEECS), vol. 17, no. 2, pp. 1109-1116, 2020.

[16] R. Wishah, M. Al-Nsour, M. Alharafsheh, S. AlKhalaileh and F. Alshbeekat, "Factors Influencing Cloud Computing in Telecommunications Companies," Indonesian Journal of Electrical Engineering and Computer Science (IJEECS), vol. 12, no. 3, pp. 1334-1339, 2018. 
[17] W. N. Wan Abd Manan and M. A. Salamat, "Concept of minimizing the response time for reducing dynamic data redundancy in cloud computing, ” Indonesian Journal of Electrical Engineering and Computer Science (IJEECS), vol. 15, no. 3, pp. 1597-1602, 2019.

[18] N. N. Kulkarni and S. A. Jain, "Checking integrity of data and recovery in the cloud environment," Indonesian Journal of Electrical Engineering and Computer Science (IJEECS), vol. 13, no. 2, pp. 626-633, 2019.

[19] Z. Benlalia, K. Abouelmehdi, A. Beni-hssane and A. Ezzati, "Comparing load balancing algorithms for web application in cloud environment, ” Indonesian Journal of Electrical Engineering and Computer Science (IJEECS), vol. 17, no. 2, pp. 1104-1108, 2020.

[20] N. L. Udaya Kumar and M. Siddappa, "Security for Virtualization in Cloud Services using Duplication Method, " Indonesian Journal of Electrical Engineering and Computer Science (IJEECS), vol. 6, no. 2, pp. 482-488, 2017.

[21] K. G. Rao, V. Rodda and B. B. Rao, "Qualitative Analysis of Recognition-based Graphical Password Authentication Schemes for Accessing the Cloud," Indonesian Journal of Electrical Engineering and Computer Science (IJEECS), vol. 7, no. 2, pp. 507-513, 2017.

[22] M. F. Mohamed Firdhous and B. H. Sudantha, "\{Cloud, IoT $\}$-powered smart weather station for microclimate monitoring," Indonesian Journal of Electrical Engineering and Computer Science (IJEECS), vol. 17, no. 1, pp. 508-515, 2020.

[23] N. Hashim, N. Norddin, F. Idris, S. N. I. Mohd Yusoff and M. Zahari, "IoT blood pressure monitoring system," Indonesian Journal of Electrical Engineering and Computer Science (IJEECS), vol. 19, no. 3, pp. 1384-1390, 2020.

[24] C. R Srinivasan, G. Charan and P C. S. Babu, "An IoT based SMART patient health monitoring system," Indonesian Journal of Electrical Engineering and Computer Science (IJEECS), vol. 18, no. 3, pp. 1657-1664, 2020.

[25] J. K. Abed and H. M. Abd-aljaba, "Smart monitor of pacemaker patient by using IoT cloud in real time," Indonesian Journal of Electrical Engineering and Computer Science (IJEECS), vol. 18, no. 1, pp. 158-166, 2020. 